\title{
Hypospadias in a male infant with an unusual mosaic 45,X/46,X,psu idic(Y)(p11.32)/46,XY and haploinsufficiency of $S H O X$ : A case report
}

\author{
YAN-MEI SI ${ }^{*}$, YUAN DONG*, WEI WANG, KE-YAN QI and XIN WANG \\ Department of Genetics and Metabolism, Beijing Obstetrics and Gynecology Hospital, Capital Medical \\ University, Beijing Maternal and Child Health Care Hospital, Beijing 100026, P.R. China
}

Received December 8, 2015; Accepted February 1, 2017

DOI: $10.3892 / \mathrm{mmr} .2017 .6569$

\begin{abstract}
A male newborn presented with hypospadias and differential testicular volumes. Short femur length was detected four times during pregnancy, at 23, 31, 32 and 33 weeks, by ultrasonographic examination. Chromosome analysis was performed on peripheral lymphocytes obtained from the infant and his parents. Fluorescent in situ hybridization (FISH), using sex determining region Y (SRY)/DXZ1 and DYZ3 probes, was performed to verify the deletion of the SRY gene (located on Yp11.3 region) and the activation of $Y$ chromosomal centromeres. Single nucleotide polymorphism (SNP)-array comparative genomic hybridization (CGH) was used to detect copy number variations in the infant. The results revealed a $\sim 2.2 \mathrm{Mb}$ mircodeletion on Yp11.32 containing the short stature homeobox (SHOX) gene. According to the above examinations, the abnormal $\mathrm{Y}$ chromosome of the patient was identified as a dicentric derivate of the $\mathrm{Y}$ chromosome with pseudoinactivation of one of the two centromeres. The karyotype is therefore: 45,X[20]/46,X,idic(Y)(p11.3). ish psu idic(Y)(p11.3) (SRY++, DYZ3++). array Yp11.32 $(118,551-2,393,500) \times 0[26] / 46, X, i \operatorname{shY}(S R Y+$, DYZ3+)[4]. The combination of cytogenetic, FISH and SNP-array CGH technologies was beneficial for diagnosing the karyotype accurately, predicting the prognosis, and preparing an effective treatment plan for the patient.
\end{abstract}

Correspondence to: Dr Yuan Dong, Department of Genetics and Metabolism, Beijing Obstetrics and Gynecology Hospital, Capital Medical University, Beijing Maternal and Child Health Care Hospital, 251 Yaojiayuan Road, Chaoyang, Beijing 100026, P.R. China

E-mail: dongyuancg@163.com

*Contributed equally

Key words: haploinsufficiency of short stature homeobox, dicentric $\mathrm{Y}$ hypospadias, mosaicism, short stature

\section{Introduction}

A dicentric Y chromosome has 2 centromeres and is a common abnormal structural rearrangement of the $\mathrm{Y}$ chromosome that is unstable during cell division. It is likely to generate various cell lines and most affected patients that have been reported are chromosomal mosaics, typically including the $45, \mathrm{X}$ cell line (1). If there are completely symmetrical arms on the dicentric chromosome, it is considered an isodicentric chromosome. Regardless of the proportion of the two cell lines in peripheral blood, the phenotypic spectrum of chromosomal mosaics of all ages may vary widely and includes healthy infertile males, females with or without Turner syndrome, individuals with ambiguous genitalia and mixed gonadal dysgenesis (2-6). However, there are few reports regarding patients with three different cell lines, particularly the 46,XY normal karyotype.

Hypospadias is a common abnormality of the external genitalia in males, and patients with hypospadias may exhibit chromosomal abnormalities. Kojima et al (7) assessed 400 patients who underwent surgery to repair hypospadias and identified chromosomal anomalies in $22(6 \%)$.

The present case report is of a hypospadiac male infant with a 45,X/46,X,psu idic(Y)(p11.32)/46,XY karyotype. The patient carried a pseudodicentric $\mathrm{Y}$ chromosome with the break point located at pseudoautosomal region 1 (PAR1). To the best of our knowledge, this is the first description of a mosaic karyotype containing three cell lines. The proband manifested short stature due to haploinsufficiency of short stature homeobox $(S H O X)$, confirmed through single nucleotide polymorphism (SNP)-array comparative genomic hybridization (CGH) detection. The combination of cytogenetic, fluorescence in situ hybridization (FISH) and SNP-array CGH technologies was beneficial for diagnosing the karyotype accurately, predicting the prognosis and preparing an effective treatment plan.

\section{Case report}

A newborn infant was investigated due to hypospadias and differential testicular volumes (Fig. 1). Written informed consent was obtained from the parents. The parents of the infant had not had contact with hazardous substances and were healthy 28 -year-olds. The karyotypes of the parents were 
A

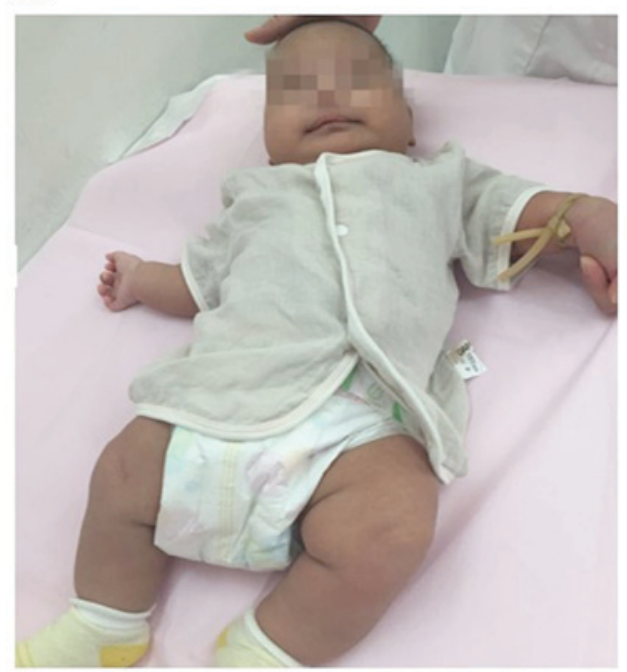

C

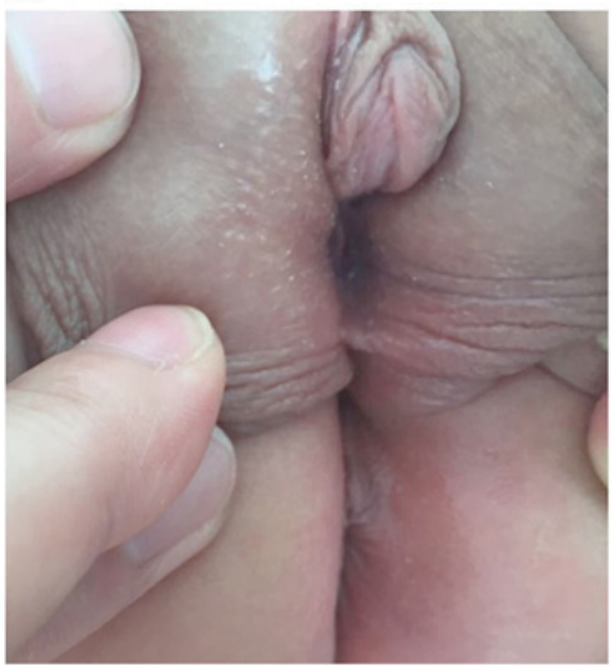

B

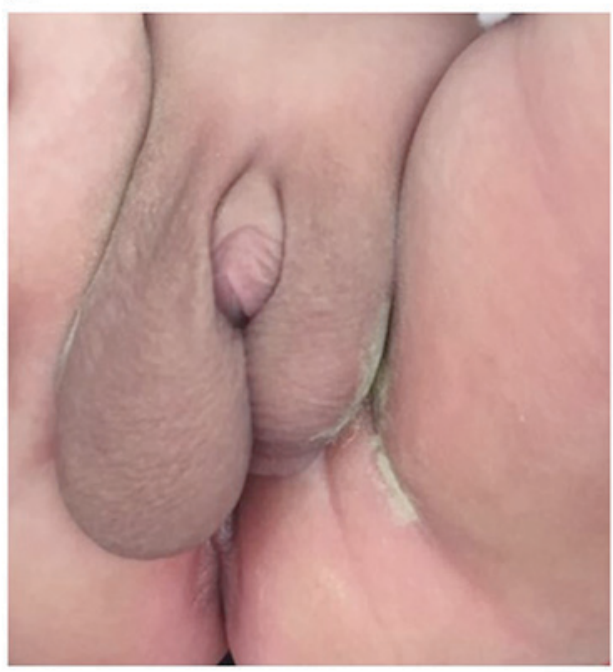

D

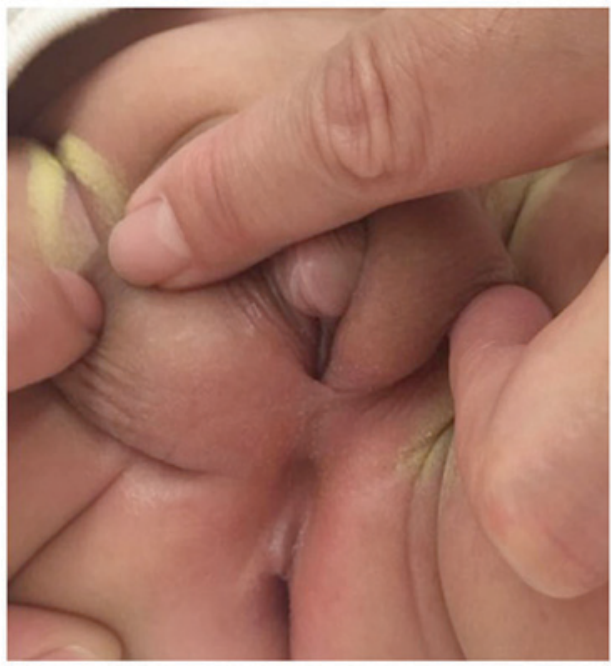

Figure 1. (A) The male infant. (B) Different sizes of bilateral testes. (C and D) Hypospadias of the patient.

normal male (46, XY) and normal female (46, XX). There was no known parental consanguinity and family history was negative for hypospadias and short adult stature. During the pregnancy, there was no evidence of intrauterine growth retardation except for short femur length at 23, 31, 32 and 33 weeks. Due to the low risk of Down's syndrome, karyotype analysis of amniotic cells was not performed. At 6 weeks pregnant, the infant's mother (gravida 1 para 1) had taken progesterone for approximately one month due to low progesterone levels. Due to hypothyroidism at 36 weeks pregnancy, levothyroxine sodium tablets had been taken.

Cesarean delivery occurred at 38 weeks of gestation. The birth weight of the infant was $3,150 \mathrm{~g}$ ( -0.5 standard deviation; $3,300 \mathrm{~g}$ being the average weight of a healthy male Chinese newborn) and a length of $47 \mathrm{~cm}$ (-1.5 standard deviation; $49.9 \mathrm{~cm}$ being the average length of a healthy male Chinese newborn). The Apgar score was 9/10/10. The infant was examined at a pediatric day-surgery center (Department of Pediatric Surgery, Beijing Children's Hospital, Capital Medical University, Beijing, China) at 29 days. Inguinal ultrasonography revealed no uterus or ovaries. Bilateral testes were both located in the scrotum, with a left testicular size of $0.8 \times 0.4 \mathrm{~cm}$ and a right testicular size of $1.2 \times 0.7 \mathrm{~cm}$. There was a liquid dark space of $\sim 2.5 \times 0.8 \mathrm{~cm}$ on the testicular sheath membrane cavity. No abnormalities were detected regarding bilateral testicular parenchyma, blood supply and bilateral spermatic cords. An intra-abdominal investigation of laparoscopy was not performed. At 56 days old, the weight of the infant was $6,100 \mathrm{~g}$ ( 0.5 standard deviation; 5,600 $\mathrm{g}$ being the average) and length was $56 \mathrm{~cm}$ (-1.5 standard deviation; $58.4 \mathrm{~cm}$ being the average). Averages provided are according to the World Health Organization standards of child growth.

The serum reproductive hormone levels of the patient were detected at 56 days (Beijing Obstetrics and Gynecology Hospital, Capital Medical University, Beijing, China) by immunoassay, using a UniCel ${ }^{\circledR}$ DxI 800 Immunoassay system (Beckman Coulter, Inc., Brea, CA, USA), and were normal for luteinizing hormone (7.22 IU/1; normal range, 1.24-8.62 IU/1), follicle-stimulating hormone (4.02 IU/1; normal range, 1.27-19.26 IU/l), estradiol (12.37 pg/ml; normal range, $<47 \mathrm{pg} / \mathrm{ml})$, progesterone $(0.70 \mathrm{ng} / \mathrm{ml}$; normal range, $0.10-0.84 \mathrm{ng} / \mathrm{ml})$ and testosterone $(1.13 \mathrm{ng} / \mathrm{ml}$; normal range, 

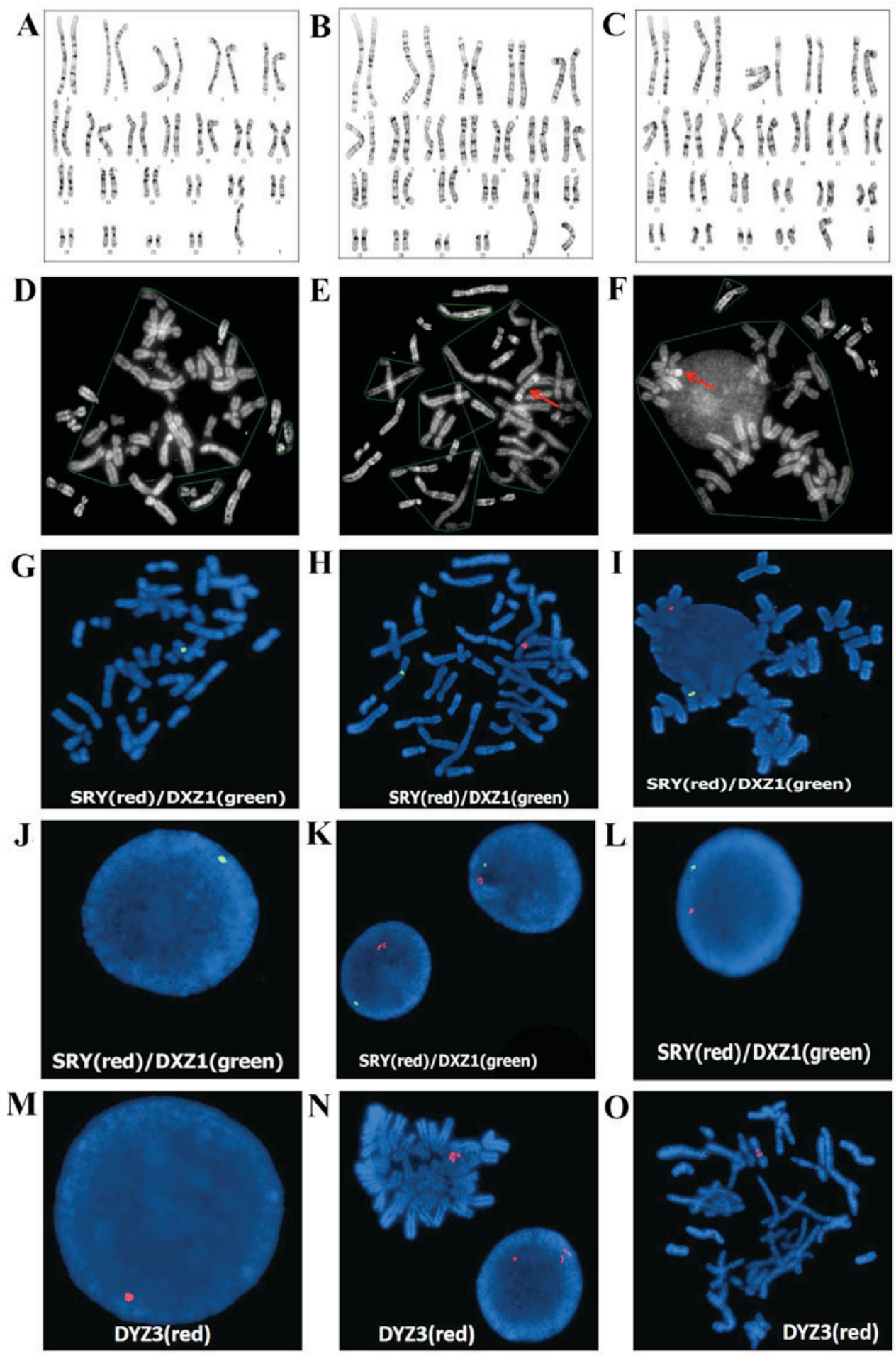

Figure 2. (A-C) Giemsa banding and (D-F) QFQ banding, of (E) Dic(Y) and (F) normal Y. SRY/DXZ1 probe detection in (G-I) metaphase cells and (J-L) interphase cell nuclei. DYZ3 probe detection in $(\mathrm{M})$ interphase nuclei cell $(46, \mathrm{XY})$ and $(\mathrm{N}$ and $\mathrm{O})$ metaphase cells $[46, \mathrm{X}$,psu idic $(\mathrm{Y})(\mathrm{p} 11.3)]$. SRY, sex determining region $\mathrm{Y}$.

1.75-7.81 ng/ml). However, prolactin levels were elevated (37.49 ng/ml; normal range, $2.64-13.13 \mathrm{ng} / \mathrm{ml})$.

Chromosomal karyotype and FISH analysis. Lymphocytes were obtained at 5 days after birth; $2 \mathrm{ml}$ of peripheral blood was collected, and then $0.5 \mathrm{ml}$ of peripheral blood lymphocytes were cultured in lymphocyte culture medium (Yishengjun; BaiDi Bio-Technology, Guangzhou, China) at $37^{\circ} \mathrm{C}$ for $72 \mathrm{~h}$, followed by $50 \mu \mathrm{g} / \mathrm{ml}$ colchicine treatment (Yishengjun; BaiDi Bio-Technology) $1 \mathrm{hbefore} \mathrm{culture} \mathrm{termination} \mathrm{to} \mathrm{arrest} \mathrm{mitoses.}$ The lymphocytes were hypotonically treated in $0.075 \mathrm{M} \mathrm{KCl}$ and fixed in methanol:acetic acid (3:1); then G-banding was performed. Immunoassay was performed to detect the infant's serum reproductive hormone levels. Chromosomal analysis of peripheral lymphocytes revealed the presence of 3 cell lines. In 23 of 50 (46\%) analyzed metaphases, a numerically 
abnormal karyotype was detected: 45,X (Fig. 2A). In 24 of 50 (48\%) metaphases, a suspected isodicentric Y chromosome was detected: 46,X,?idic (Y)(p11.3) (Fig. 2B). In 3 of 50 (6\%) metaphases, a normal karyotype was detected: 46,XY (Fig. 2C). Additional QFQ-banding techniques revealed that the heterochromatic region of the long arm of the $\mathrm{Y}$ chromosome was none, two copies and one copy in the above three cell lines, respectively (Fig. 2D-F). The karyotype was designated as $45, \mathrm{X} / 46, \mathrm{X}$, ?idic(Y)(p11.3)/46,XY.

FISH was performed using a sex-determining region $Y$ (SRY)/Vysis CEP X (DXZ1) probe and a Vysis CEP Y (DYZ3) probe on the SRY region of Yq11.3, the centromeric region of the $\mathrm{X}$ chromosome and $\mathrm{Y}$ chromosome (Vysis; Abbott Molecular, Inc., Des Plaines, IL, USA). The probes were denatured for $2 \mathrm{~min}$ at $73^{\circ} \mathrm{C}$. The hybridization mixture

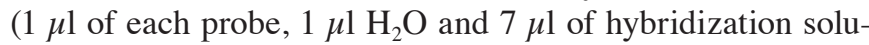
tion) was applied to each slide and covered with a coverslip $20 \times 20 \mathrm{~mm}$. The hybridization mixture was a $70 \%$ solution of dextran sulphate and formamide in saline-sodium citrate (SSC) buffer (pH 7). Each slide was then sealed with rubber cement before hybridization was carried out overnight in a moist chamber at $37^{\circ} \mathrm{C}$. After hybirdization, the slides were washed for $3 \mathrm{~min}$ in a solution of X0.4 SSC at $73^{\circ} \mathrm{C}$ and a second time for $30 \mathrm{sec}$ in a solution of X2 SSC/0.1\% Nonidet P40. Following the final wash, slides were air dried in the dark. The slides were counterstained with a solution of 4', 6-Diamidine-2'-phenylindole dihydrochloride (DAPI II; Vysis Inc., Downers Grove, IL, USA) diluted in an antifade mounting medium. The SRY/DXZ1 probe was successfully hybridized to metaphase cells (Fig. 2G-I) and interphase cell nuclei (Fig. 2J-L). Fig. 2J-L demonstrates that there was no SRY signal in Fig. 2J, but there were two signals and one signal on the SRY region of Yq11.3 in (Fig. 2K and L, respectively). In addition, there was one signal in the centromeric regions of the X chromosome on metaphase cells (Fig. 2G-I) and one signal in interphase cell nuclei, respectively (Fig. 2J-L). One red signal revealed the active $\mathrm{Y}$ centromere on interphase cell nuclei (46,XY; Fig. 2M). Two red signals revealed the inactive $\mathrm{Y}$ centromere and one red signal revealed the active $\mathrm{Y}$ centromere on a metaphase cell [46,X,psu idic (Y)(p11.3); Fig. 2N-O]. According to these results, the abnormal Y chromosome was identified as a dicentric derivate of the $\mathrm{Y}$ chromosome with psuedoinactivation of one of the two centromeres (Fig. 3). The karyotype of the infant was designated as 45,X[20]/46,X,?idic (Y)(p11.3).ish psu idic(Y)(p11.3) (SRY++, DYZ3++)[26]/46, $\mathrm{X}$,ish Y (SRY+, DYZ3+)[4].

SNP-array CGH analysis. Peripheral blood $(1 \mathrm{ml})$ containing $2.25 \mathrm{mg} / \mathrm{ml}$ EDTA was sent to Be Creative Lab Co. Ltd (Beijing, China) for processing and an Affymetrix CytoScan ${ }^{\circledR} 750 \mathrm{~K}$ (Affymetrix, Inc., Santa Clara, CA, USA) gene chip was used to determine the SNPs and copy number variations $(\mathrm{CNVs})$. SNP-array CGH detected a deletion on the pseudoautosomal region of the Y chromosome (Yp11.32) that encompassed $\sim 2.2 \mathrm{Mb}$ (Fig. 4). Thus, the SNP-array CGH results of the patient were $\operatorname{arr}[\mathrm{hg} 19] \mathrm{Yp} 11.32(118,551-2,393,500) \mathrm{x} 0$. When the results of chromosome karyotype analysis, FISH and SNP-array CGH were combined, it was possible to identify the precise breakage of the abnormal Y chromosome on Yp11.32. The results were analyzed using the

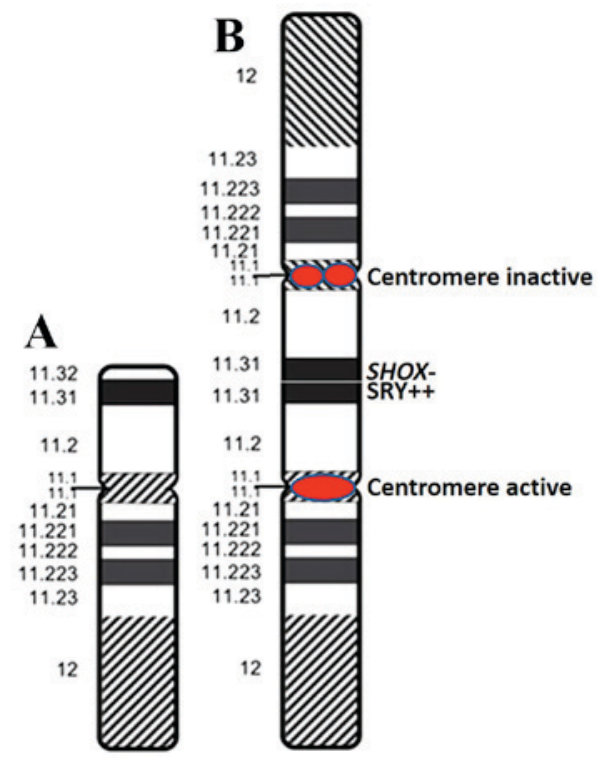

Figure 3. Diagrams of (A) a normal Y chromosome and (B) a 46,X,psu idic (Y)(p11.32).

Online Mendelian Inheritance in Man (OMIM) database (omim.org/), Gene Review (Reviews of genetic disorders/syndromes and lab testing; www.ncbi.nlm.nih. gov/gtr/\#genereviews), the International Standards for Cytogenomic Arrays (ISCA) and the Consortium Clinical CNV Database (www.ncbi.nlm.nih.gov/dbvar). Data analysis revealed that the $2.2 \mathrm{Mb}$ deletion encompassed $\sim 20$ OMIM genes, including SHOX. No clinically significant microdeletions or microduplications on other chromosomes were observed.

\section{Discussion}

The phenotypic spectrum of $45, \mathrm{X} / 46, \mathrm{XY}, \operatorname{dic}(\mathrm{Y})$ mosaicism is broad and variable. Table I presents previous studies regarding patients with differing sex, age, proportions of cell lines and break points. It has been suggested that the diverse clinical phenotypes are dependent on the proportions of the different cell lines, and the variable sites of breakage and fusion on $\mathrm{Y}$ chromosomes.

The present study reported a patient with hypospadias and a mosaicism karyotype of 3 cell lines 45,X[23]/46,X,?idic(Y) (p11.32)[24]/46,XY[3]. The $\operatorname{dic}(Y)$ chromosome of the male infant was a result of meiosis I exchange between sister chromatids at the pseudoautosomal region, followed by centromere misdivision at meiosis II during spermatogenesis in the father. Another cause probably occurred during the first division following fertilization (8). The most important reason for chromosomal breakage and reunion is exposure to hazardous substances including radiation, medication, chemical and biological factors. Although the parents of the present infant denied contact with the above factors, the presence or absence of hazardous material tends to be unpredictable in daily life.

The SRY gene, located at the tip of the Y short arm (Yp11.3), is a critical switch that results in testis development (9). To confirm whether the break point on the $\mathrm{Y}$ chromosome involved SRY and sex differentiation, FISH was performed on 

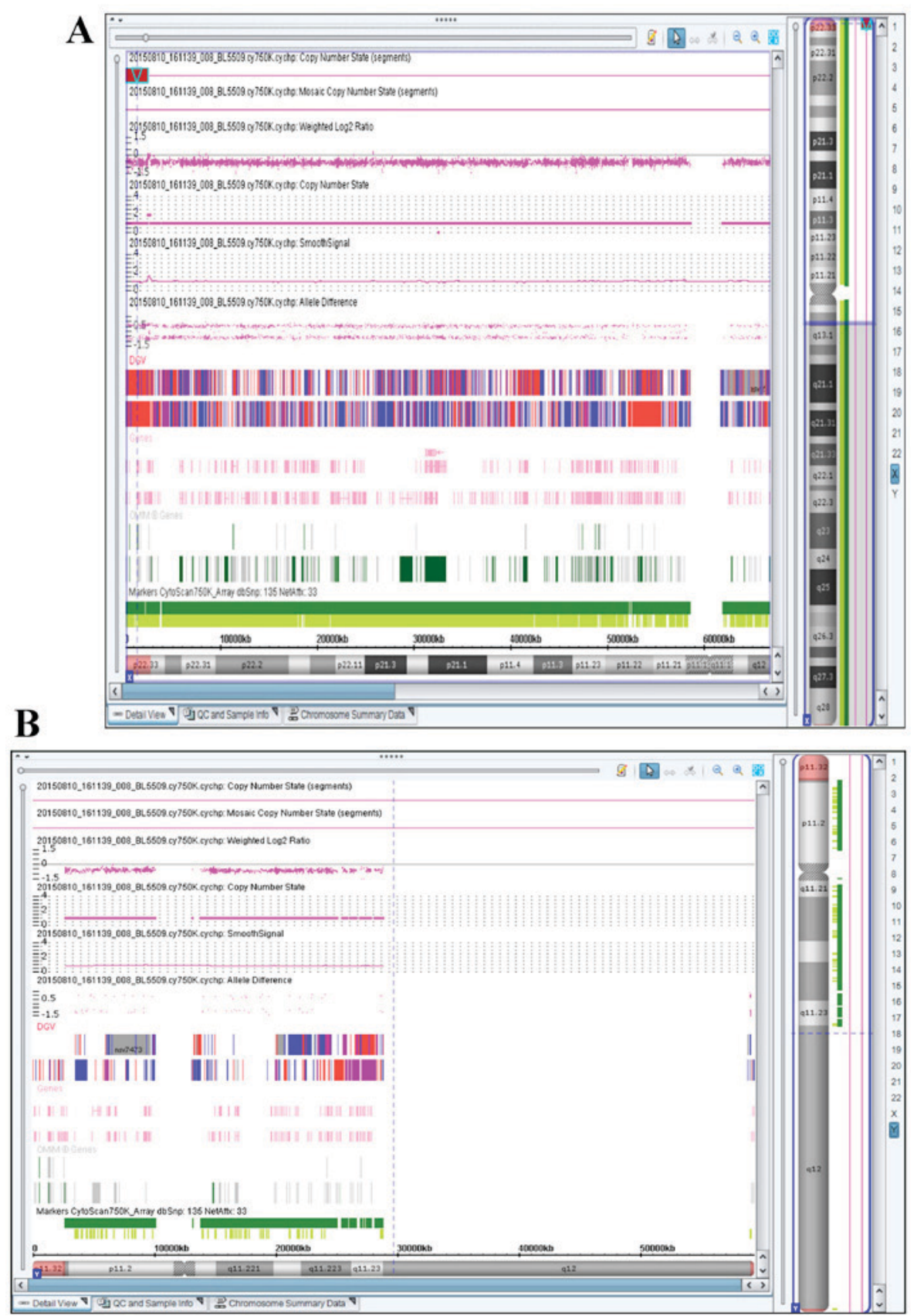

Figure 4. Single nucleotide polymorphism-array profiles of (A) an X chromosome with one copy of SHOX on Xp22.33 and (B) a Y chromosome with no copy of SHOX on Yp11. SHOX, short stature homeobox.

metaphase cells and interphase cell nuclei using a SRY/DXZ1 probe. The results revealed that there were two signals on $\operatorname{dic}(\mathrm{Y})$, which suggested that the breakage was on Yp11.3. A DYZ3 probe was additionally used to verify the activity of the two Y chromosomal centromeres on $\operatorname{dic}(\mathrm{Y})$. The rearranged $\mathrm{Y}$ chromosome was of dicentric structure in which only one centromere was active, meaning that the aberrant Y chromosome was stable in mitotic cell division.

SHOX, located in the PAR1 on the tip of the short arms of the X and Y sex chromosomes (Xp22.33 and Yp11.32), is comprised of $\sim 2.6 \mathrm{Mb}$ (10). To evaluate the development of the patient and to confirm the deficiency of SHOX gene on the terminal of the short arm of the Y chromosome, SNP-array $\mathrm{CGH}$ was used for genome-wide sequencing and to identify
CNVs. Only one copy of SHOX was detected on Xp22.33. However, the copy on Yp11.32 was deletion. This revealed that the break point on $\operatorname{dic}(\mathrm{Y})$ chromosome was Yp11.23, and it had lost the pseudoautosomal region. The deficiency of SHOX causes Leri-Weill Syndrome, which is characterized by short stature and abnormal limbs (11). This indicates that the short femur length during pregnancy and short stature following birth in the infant described in the present study were due to the deletion of the short arm end of the Y chromosome and the haploinsufficiency of the SHOX gene. Previous evidence regarding the use of recombinant growth hormone in patients with SHOX deficiency has indicated the beneficial effect of this treatment, which improved growth speed and final height (12). 


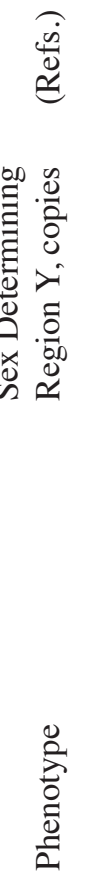

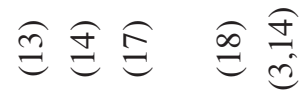

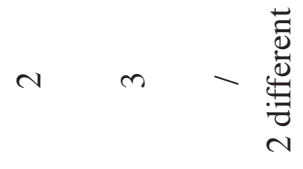

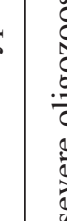

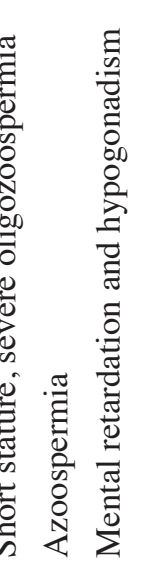



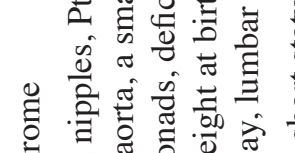

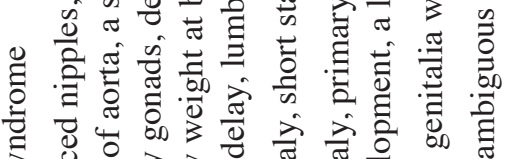

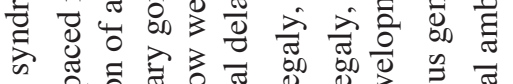

क के

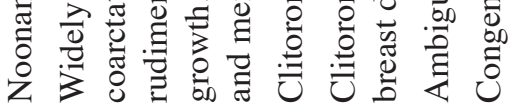

in

宓离.芯:0

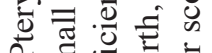

․ㅡㅁ

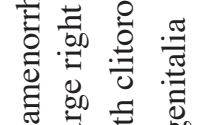

造离

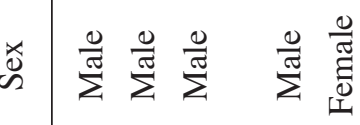

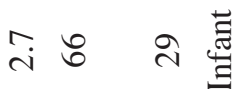

$\sqrt{\sqrt{2}}$

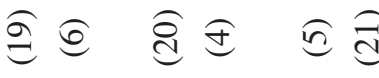

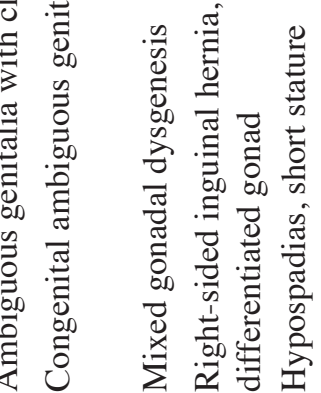

突

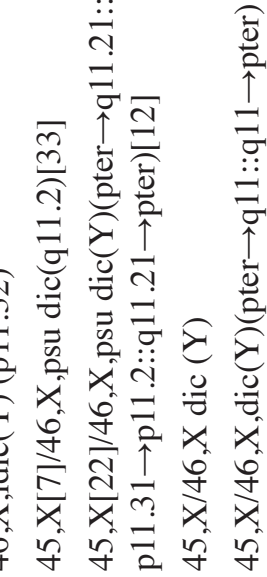

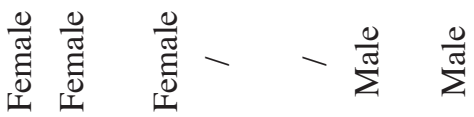

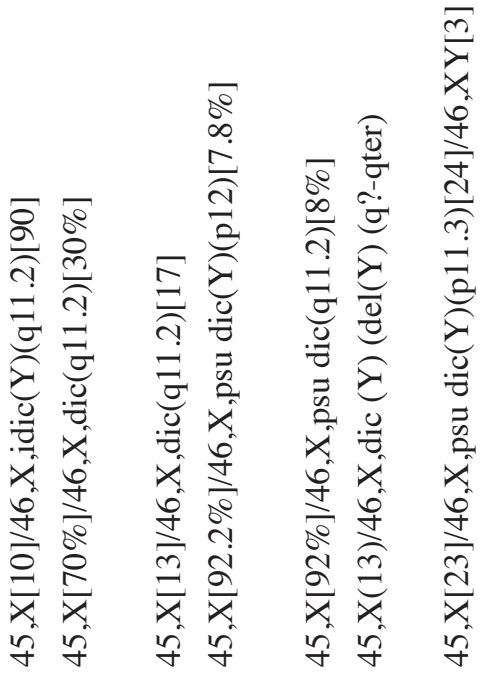

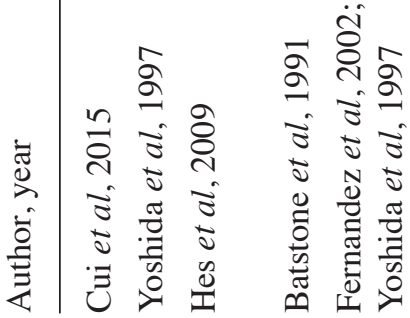

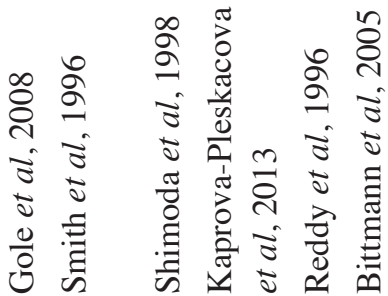

$\overrightarrow{0}$
$\overline{0}$
0
0
0
0
0
0
0
0 
It is likely that this infant will suffer infertility upon maturation. Multiple previous reports have observed that male patients with $45, \mathrm{X} / 46, \mathrm{X}, \operatorname{dic}(\mathrm{Y})$ exhibit azoospermia or oligozoospermia (2,13-15). The cause of spermatogenic failure may be explained by the presence of an abnormal Y chromosome that may not form a sex vesicle, which appears to be necessary for the completion of the meiosis process and the formation of sperm, or the presence of the 45,X cell line (16).

In conclusion, the present study reports the case of an 8-week-old hypospadiac male infant with 45,X/46,X,psu $\operatorname{idic}(\mathrm{Y})(\mathrm{p} 11.32) / 46, \mathrm{XY}$ mosaicism and haploinsufficiency of SHOX. Doctors and genetic consultants must pay greater attention to pregnant women with low risk of prenatal screening and ultrasonic structural abnormalities. The combination of cytogenetic, FISH and SNP-array CGH technologies was beneficial for diagnosing the karyotype accurately, predicting the prognosis, and preparing an effective treatment plan for the patient.

\section{Acknowledgements}

The authors thank the patient and his family for participating in the present study, and all staff of the Be Creative Lab Co., Ltd. (Beijing, China). The present study was supported by the Basic-Clinical Scientific Research Cooperation Fund, Capital Medical University (grant no. 15JL76) and the Beijing Obstetrics and Gynecology Hospital, Capital Medical University (grant no. fcyy201534).

\section{References}

1. Hsu LY: Prenatal diagnosis of 45,X/46,XY mosaicism-a review and update. Prenat Diagn 9: 31-48, 1989.

2. Codina-Pascual M, Oliver-Bonet M, Navarro J, Starke H, Liehr T, Gutierrez-Mateo C, Sánchez-García JF, Arango O, Egozcue J and Benet J: FISH characterization of a dicentric Yq (p11.32) isochromosome in an azoospermic male. Am J Med Genet A 127A: 302-306, 2004.

3. Fernandez R, Marchal JA, Sanchez A and Pasaro E: A point mutation, R59G, within the HMG-SRY box in a female 45,X/46,X, psu dic(Y) (pter->q11::q11->pter). Hum Genet 111: 242-246, 2002.

4. Kaprova-Pleskacova J, Snajderova M, Stoop J, Koudova M, Kocarek E, Novotna D, Drop SL, Obermannova B, Lebl J, Oosterhuis JW and Looijenga LH: 45,X/46,X,psu dic(Y) gonadal dysgenesis: Influence of the two cell lines on the clinical phenotype, including gonadal histology. Sex Dev 7: 282-288, 2013.

5. Reddy KS, Sulcova V, Ho CK, Conner ED and Khurana A: An infant with a mosaic $45, \mathrm{X} / 46, \mathrm{X}$,psu dic(Y) (pter-> q11.2::q11.2->pter) karyotype and mixed gonadal dysgenesis studied for extent of mosaicism in the gonads. Am J Med Genet 66: 441-444, 1996.

6. Smith YR, Stetten G, Charity L, Isacson C, Gearhart JP and Namnoum AB: Ambiguous genitalia in an elderly woman with a mosaic 45,X/46,X, $\operatorname{dic}(\mathrm{Y})(\mathrm{Q} 11.2)$ karyotype. Urology 47: 259-262, 1996.

7. Kojima Y, Hayashi Y, Yanai Y, Tozawa K, Sasaki S and Kohri K: Molecular analysis of hypospadias in a boy with dicentric $\mathrm{Y}$ chromosome. J Urol 165: 1244-1245, 2001.

8. Fernandez R and Pasaro E: Molecular analysis of an idic(Y)(qter ->p11.32::p11.32->qter) chromosome from a female patient with a complex karyotype. Genet Mol Res 5: 399-406, 2006.

9. Sinclair AH, Berta P, Palmer MS, Hawkins JR, Griffiths BL, Smith MJ, Foster JW, Frischauf AM, Lovell-Badge R and Goodfellow PN: A gene from the human sex-determining region encodes a protein with homology to a conserved DNA-binding motif. Nature 346: 240-244, 1990

10. Binder G: Short stature due to SHOX deficiency: Genotype, phenotype, and therapy. Horm Res Paediatr 75: 81-89, 2011.
11. Shears DJ, Vassal HJ, Goodman FR, Palmer RW, Reardon W, Superti-Furga A, Scambler PJ and Winter RM: Mutation and deletion of the pseudoautosomal gene SHOX cause Leri-Weill dyschondrosteosis. Nat Genet 19: 70-73, 1998.

12. Blum WF, Ross JL, Zimmermann AG, Quigley CA, Child CJ, Kalifa G, Deal C, Drop SL, Rappold G and Cutler GB Jr: GH treatment to final height produces similar height gains in patients with SHOX deficiency and Turner syndrome: Results of a multicenter trial. J Clin Endocrinol Metab 98: E1383-E1392, 2013.

13. Cui YX, Wang WP, Li TF, Li WW, Wu QY, Li N, Zhang C, Yao Q, Hu YA and Xia XY: Clinical and cytogenomic studies in a case of infertility associated with a nonmosaic dicentric $Y$ chromosome. Andrologia 47: 477-481, 2015.

14. Yoshida A, Nakahori Y, Kuroki Y, Motoyama M, Araki Y, Miura K and Shirai M: Dicentric Y chromosome in an azoospermic male. Mol Hum Reprod 3: 709-712, 1997.

15. Sasagawa I, Ishigooka M, Kato T, Hayami S, Hashimoto T and Nakada T: Dicentric Y chromosome without evidence of mosaicism in an azoospermic male. Scand J Urol Nephrol 30: 75-76, 1996.

16. Hamerton JL, Canning N, Ray M and Smith S: A cytogenetic survey of 14,069 newborn infants. I. Incidence of chromosome abnormalities. Clin Genet 8: 223-243, 1975.

17. Hes FJ, Madan K, Rombout-Liem IS, Szuhai K, Sørensen H, van Amstel HK, Bakker E, Visser TJ, Smit JW and Hansson K: Multiple genomic aberrations in a patient with mental retardation and hypogonadism: 45,X/46,X,psu $\operatorname{dic}(\mathrm{Y})$ karyotype, thyroid hormone receptor beta (THRB) mutation and heterozygosity for Wilson disease. Am J Med Genet A 149A: 2231-2235, 2009.

18. Batstone PJ, Faed MJ, Jung RT and Gosden J: 45,X/46,X dic (Y) mosaicism in a phenotypic male. Arch Dis Child 66: 252-253, 1991.

19. Gole LA, Lim J, Crolla JA and Loke KY: Gonadal mosaicism 45,X/46,X,psu $\operatorname{dic}(\mathrm{Y})(\mathrm{q} 11.2)$ resulting in a turner phenotype with mixed gonadal dysgenesis. Singapore Med J 49: 349-351, 2008.

20. Shimoda N, Sato K, Satoh S, Ogawa O, Ito S and Kato T: Atypical true hermaphroditism with a mosaic $45, \mathrm{X} / 46, \mathrm{X}, \operatorname{dic}(\mathrm{Y})(\mathrm{q} 11.2)$ karyotype. J Urol 160: 1434-1435, 1998.

21. Bittmann S, Wieczorek D, Stallmach $\mathrm{T}$ and Ulus $\mathrm{H}$ : 45,X/46,X,dic(Y)-Mosaicism in the newborn. Klin Padiatr 217: 300-303, 2005. 